wants to privatize the system like it is in the US," he says, adding that every other health care system in the world has a mix of public and private delivery and that nobody has copied Canada's single payer system.

Raised with 2 siblings in the Montréal suburb of Longueuil, the son of a plant supervisor studied medicine at the Université de Montréal and after interning, entered a pediatrics residency. It soon lost its appeal and Ouellet shifted into radiology. "I like technology. I am an Aquarius, and believe in that. Aquarius as a sign is always thinking, always looking at the future, what is coming up."

Ouellet first worked for a hospital radiology department in Trois Rivières, while enjoying regular rotations further north in LaToque, where, for a week every fall, doctors and residents disappeared into the woods to hunt.

In 1981, he was invited to join the staff of the newly minted Cité de la Santé hospital in Laval, near Montréal. Six years later, he was head of the radiology department when the hospital's chief executive officer informed him that it would be 2 years before the hospital could purchase a CT scanner, despite heavy demand.

The administrator was more than willing to send patients to a private clinic if Ouellet and colleagues were interested in opening one, so they began raising money and opened a CT clinic in 1987, staffing it, on a rotating basis, with 5 hospital radiologists, who are allowed to toil outside the public system because CT scans, MRIs and ultrasounds, if provided outside a hospital, are not covered by the province's health plan. Each spent about $15 \%$ of their time at the clinic.

In 1997, Ouellet opened the province's first private MRI clinic, again serving patients referred by his hospital, which didn't buy its own machine until 2002. But patients also came from as far as Gatineau, some $200 \mathrm{~km}$ to the west.

Ouellet stresses that patients need a prescription to receive services at the clinics, while test results are sent directly to doctors. "It's not like the US where people can just walk in off the street and ask for a full body scan."
Those not referred by hospitals, or workers compensation or auto insurance programs, pay out of pocket unless they have private insurance, which can cover as much as $80 \%$ of costs.

Quebec's pharmacare program, with its mix of public and private insurance coverage and deductible and copayment features, is a model for potential reform, Ouellet says. He notes that prescription drugs are not covered by the Canada Health Act. But while people don't want deductibles and copayments in the rest of the health care system, they seem quite satisfied with the way the pharmacare program operates.

The CMA is ideally positioned to promote systemic change by appealing to the hearts and minds of Canadians, Ouellet adds. A solution from doctors will "be good for the patients and good for the doctors."

Ouellet also hopes to boost CMA membership among Quebec doctors, only about one-third of whom are now Quebec Medical Association (and hence CMA) members. That's long been sought and while membership has increased, particularly among medical students, the association's goal of signing up $75 \%$ of the province's doctors before this year's annual general meeting has proved elusive. - Ann Silversides, CMAJ

DOI:10.1503/cmaj.081029

\title{
Suicide fad threatens neighbours, rescuers
}

$\mathrm{J}$ apanese authorities have moved to crack down on websites listing the ingredients and the process for concocting a deadly hydrogen sulfide gas that has been used in a spate of recent "detergent suicides."

The gas, which can form a cloud that affects neighbours and rescuers, has often triggered mass evacuations.
The Peninsula Hotel in Tokyo, for example, was forced to clear patrons from 4 floors, while in Konan City, a 14-year-old girl used the gas, causing her mother to be hospitalized and 90 of her neighbours to flee their homes.

Japanese media reported that the girl stuck a sign to the bathroom door that stated "DO NOT open! Poison gas be-

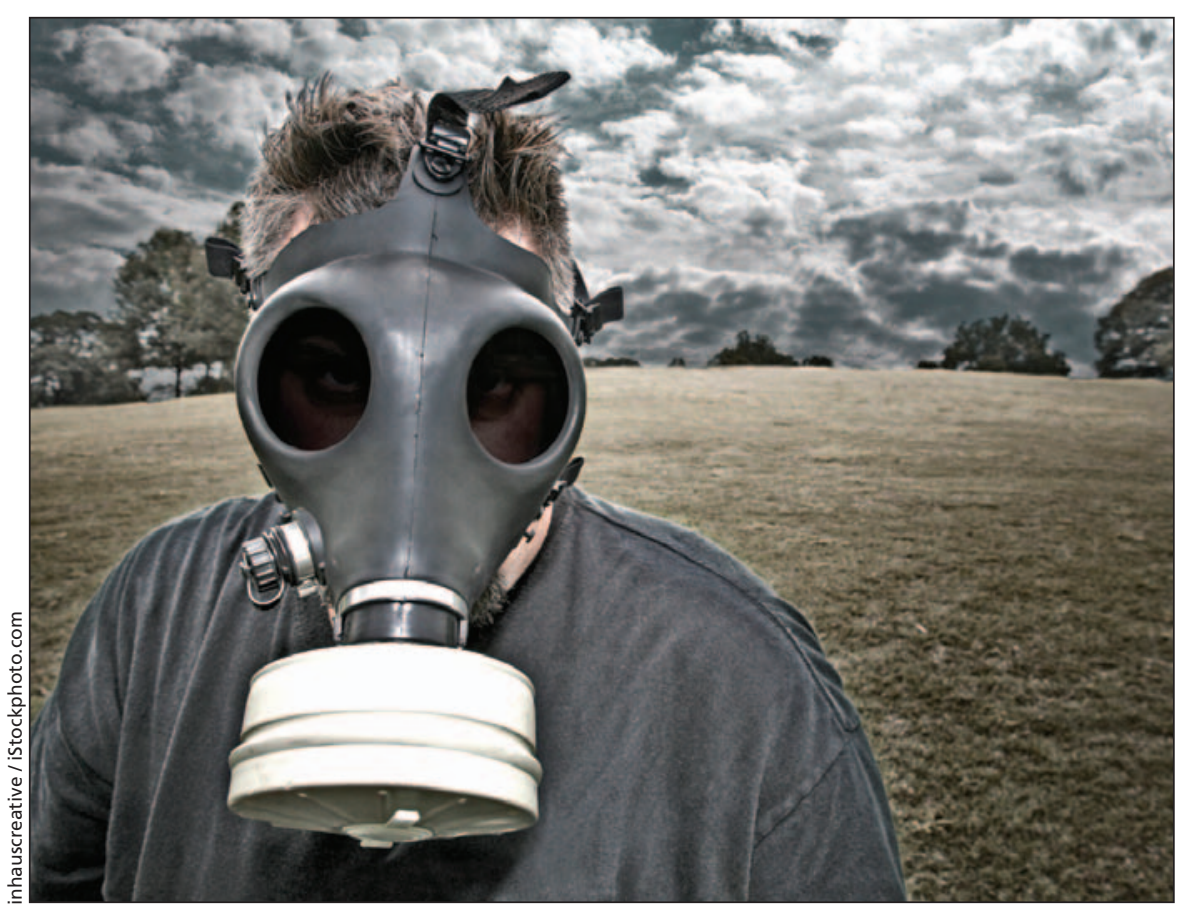

Medical workers are being forced to wear gas masks in responding to "detergent suicides" in Japan. 
ing produced!" She had printed it from the website where she'd learned how to mix the chemicals.

Since March 2008, more than 180 people have died as a result of inhaling the fumes produced by the deadly mix of common bathroom cleaning products, prompting the Japan National Police Agency to ask Internet service providers to shut down a number of websites that provided a recipe for the toxic gas.

The toxicity of hydrogen sulfide is comparable with that of hydrogen cyanide. It forms a complex bond with iron in the mitochondrial cytochrome enzymes, thereby blocking oxygen from binding and stopping cellular respiration. The victims die from suffocation or brain damage. The hydrogen sulfide gas is colourless and smells like rotten eggs, but it can paralyze the sense of smell after a few inhalations. In lower doses, it causes eye irritation, upset stomach and breathing problems.

Japan has the ninth highest suicide rate in the world. In 2006, 31155 people killed themselves, the ninth consecutive year in which suicide deaths topped 30000 . The government spends \$220 million annually on anti-suicide programs.

According to the World Health Organization (based on 1999 data), Japan had a suicide rate of 24.3 males and 11.5 females per 100000 population. By comparison, Canada's rate was 21.5 and 5.4.

Hajime Oiso, a spokesman for Japan's Ministry of Internal Affairs and Communications, says it isn't clear how many websites have now been shut down or whether that has affected the rate of detergent suicides.

Ontario's Chief Coroner, Dr. Bonita Porter, says there's no evidence the fad has spread to Canada.

But Dr. Paul Links, chair in suicide studies at the University of Toronto, says ready access to information about suicide methods invariably leads to higher rates.

It's not just instructional websites that are a problem, Links says. "In general, there is a relationship between media reporting of method and copycat suicides." — Amanda Truscott, Toronto, Ont.

DOI:10.1503/cmaj.080878

\section{Clowning around sets patients at ease}

$\mathrm{W}$ e've got to walk," says the grandmother, holding her 4year-old granddaughter's hand. Behind them, near the entrance to the cardiology ward of the Hospital for Sick Children (SickKids), trails her 7-year-old grandson.

From under the girl's shirt poke wires and tubes, which lift the fabric off her belly and are attached to a box held by straps in her father's hands.

Her eyes are wide and sad and terrified.

Bunky, a therapeutic clown dressed in blue bloomers, red suspenders and a green shirt, shuffles up and delivers a "thumbs up" to the girl.
She frowns and turns away.

Bunky hauls out green organza, wraps it around his head, bats his eyes and sputters through puckered lips. He sits on the floor and looks up at the children. He smiles and holds up a finger, as if to say: "wait." Reaching to a transparent box mounted on his yellow tricycle, Bunky pulls out a collapsed reticulated sphere and twirls it. The plastic toy expands. It dances on his fingers, spinning and growing. The boy is entranced. Bunky passes him the sphere. It promptly deflates. The boy takes it, twirls it, and it opens again. "Che bella!" exclaims the grandmother, as the girl inches closer for protection.

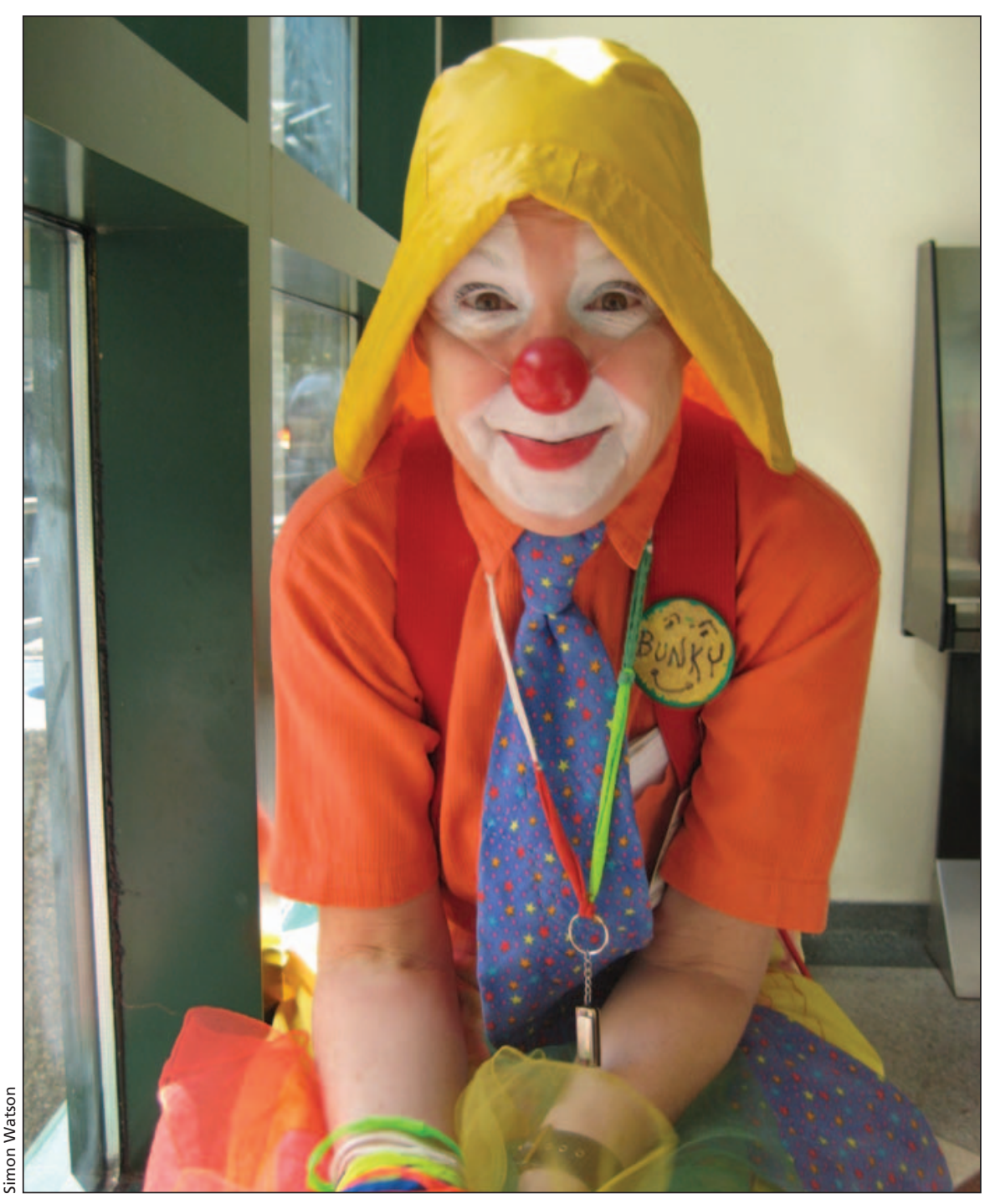

"To be happy and then be sad; sometimes the play is just through the eyes and the smile," says Joan Barrington, a.k.a. Bunky. 